\section{The presence of percutaneous endoscopic gastrostomy (PEG)-related postprocedural pneumoperitoneum}

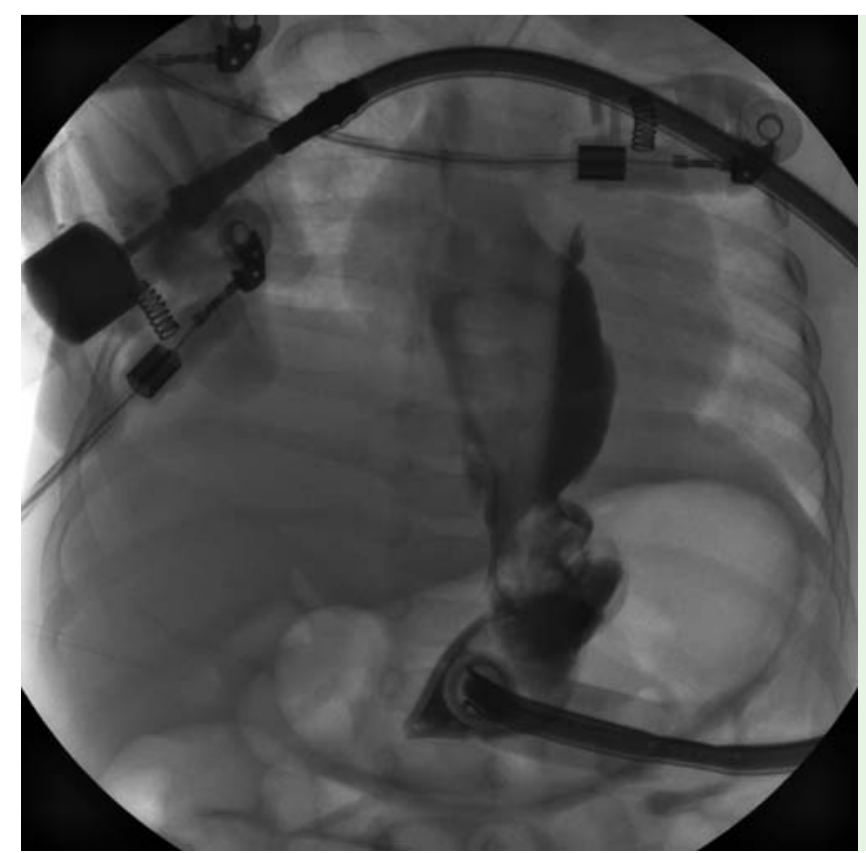

Fig. 1 The contrast material fails to fill the air-insufflated stomach and flushes the esophagus directly. Continuing images imitate an extremely dilated esophagus and possible disruption at the esophagogastric level showing extravasations. The double-contrast view obtained from the intussuscepted esophagus clearly demonstrates the nature of the complication.

Percutaneous endoscopic gastrostomy (PEG) is a good example of surgical treatments that adopt a "minimal access therapeutic approach". However, the procedure, which is also referred to as the nonsurgical technique, carries a false sense of safety, as it is associated with significant morbidity [1 - 5]. In the English literature, a wide range of reports regarding PEG insertion state that postprocedural pneumoperitoneum is a common and benign finding. The reported incidence is over $50 \%$, and the condition is generated by endoscopic air insufflation in association with needle puncture of the abdominal wall and stomach $[1,2]$.

A 3-month old boy weighing $3.7 \mathrm{~kg}$ and under ventilator support was being cared for in the intensive care unit. He rapidly developed severe respiratory distress and hypoxia following PEG (Flocare 35429, CH 18; Numico, Schiphol, The Netherlands) placement using the "pull" technique. A contrast study was obtained immediately via the gastrostomy catheter by the gastroenterologist. The image outlined a possible perforation showing extravasations (๑ Fig. 1).
A chest radiograph revealed wide pneumoperitoneum and pneumothorax (๑ Fig. 2).

Exploratory laparotomy revealed complete transection of the esophagus. An esophageal segment of approximately $3.5-\mathrm{cm}$ long was inverted and inserted in the stomach. The distal portion of the esophagus was closed, the gastrostomy replenished, and a left cervical esophagostomy was fashioned. The patient was successfully weaned from respiratory treatment and started on gastrostomy feeding within a week.

A year after the initial gastrostomy operation, the patient is awaiting a repeat operation, following two failed esophageal replacement operations performed in a tertiary center abroad.

Wilson et al. recommend either a 14- or 15-Fr tube in infants weighing less than $3.5 \mathrm{~kg}$ [5]. We may postulate that the size of the PEG tube and repeated insertion attempts may be the leading cause of the transection process in our case. We believe that the double-contrast view obtained from the intussuscepted esophagus is unique and pathognomonic in demon-

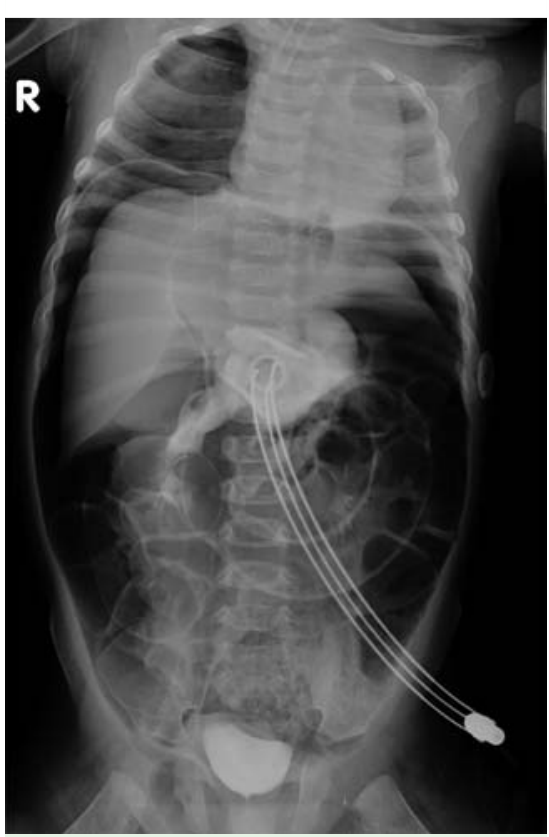

Fig. 2 Chest radiograph obtained in the intensive care unit showing wide pneumoperitoneum and pneumothorax on the right side.

strating a transected esophageal remnant due to PEG complication. Our case represents an extremely rare but morbid complication, which emphasizes the need for careful intervention, particularly in the very small infant. An aggressive surgical approach towards esophageal reconstructive surgery must be avoided, and postponed until successful recovery is maintained.

Endoscopy_UCTN_Code_CPL_1AH_2AI

\section{B. H. Güvenç ${ }^{1}$, K. Raşa ${ }^{2}$, S. Güvenç ${ }^{3}$}

Department of Pediatric Surgery, Anadolu Medical Center, Kocaeli, Turkey

2 Department of Surgery, Anadolu Medical Center, Kocaeli, Turkey

3 Intensive Care Unit, Anadolu Medical Center, Kocaeli, Turkey 


\section{References}

1 Schrag SP, Sharma R, Jaik NP et al. Complications related to percutaneous endoscopic gastrostomy (PEG) tubes. A comprehensive clinical review. J Gastrointest Liver Dis 2007; 16: 407-418

2 Varnier A, Iona L, Dominutti MC et al. Percutaneous endoscopic gastrostomy: complications in the short and long term follow-up and efficacy on nutritional status. Eur Med Phys 2006; 42: $23-26$
3 Ségal D, Michaud L, Guimber D et al. Late-onset complications of percutaneous endoscopic gastrostomy in children. J Pediatr Gastroenterol Nutr 2001; 33: 495-500

4 Khattak IU, Kimber C, Kiely EM, Spitz L. Percutaneous endoscopic gastrostomy in paediatric practice: complications and outcome. J Pediatr Surg 1998; 33: 67-72

5 Wilson L, Oliva-Hemker M. Percutaneous endoscopic gastrostomy in small medically complex infants. Endoscopy 2001; 33: $433-436$
Bibliography

DOI $10.1055 / \mathrm{s}-0029-1215068$

Endoscopy 2009; 41: E269-E270

(c) Georg Thieme Verlag KG Stuttgart · New York . ISSN 0013-726X

\section{Corresponding author}

B. H. Güvenç, MD

Anadolu Medical Center

41400, Gebze

Kocaeli

Turkey

Fax: +90-262-6540529

guvench@superonline.com 